\title{
Ácidos graxos da gema e composição do ovo de poedeiras alimentadas com rações com farelo de coco
}

\author{
Suely Carvalho Santiago Barreto(1), Jorge Fernando Fuentes Zapata ${ }^{(1)}$, Ednardo Rodrigues Freitas ${ }^{(1)}$, \\ Maria de Fátima Freire Fuentes ${ }^{(1)}$, Ronaldo Ferreira do Nascimento(1), Regilda Saraiva dos Reis Moreira Araújo( ${ }^{(2)}$ \\ e Adriany das Graças Nascimento Amorim(1)
}

(1)Universidade Federal do Ceará, Caixa Postal 12.168, CEP 60021-190 Fortaleza, CE. E-mail: suely_barreto@ig.com.br, zapata@ufc.br, ednardo@ufc.br, fatimaf@ufc.br, ronaldo@ufc.br, adrianyamorim@hotmail.com (2)Universidade Federal do Piauí, Dep. de Nutrição, Campus Ministro Petrônio Portela, Bloco 13, Bairro Ininga, CEP 64049-550 Teresina, PI. E-mail: regmarjoao@uol.com.br

\begin{abstract}
Resumo - O objetivo deste trabalho foi avaliar o efeito da inclusão do farelo de coco (FC) na ração e do tempo de alimentação de poedeiras comerciais, sobre os ácidos graxos da gema e os componentes do ovo. O delineamento foi em esquema fatorial 5x2, com cinco níveis de inclusão do FC (0, 5, 10, 15 e 20\%) e dois tempos de alimentação (14 e 28 dias). Foram avaliados o peso e as porcentagens de albúmen, gema e casca dos ovos, bem como os sólidos e lipídios totais e o perfil de ácidos graxos das gemas. A inclusão do FC e o tempo de alimentação influenciaram apenas a proporção de ácido mirístico na gema, que aumentou com a inclusão do FC aos 28 dias de alimentação. Os ácidos esteárico e oléico variaram somente com o tempo de alimentação, e as maiores concentrações foram obtidas aos 28 dias. A relação de ácidos graxos poliinsaturados para ácidos graxos saturados da gema diminuiu a partir de $10 \%$ de inclusão e aumentou com o tempo de alimentação das aves. O uso de farelo de coco, na ração de poedeiras comerciais, não influencia a proporção dos componentes do ovo, apenas altera a concentração do ácido mirístico da gema.
\end{abstract}

Termos para indexação: gema do ovo, sólidos totais, perfil de ácidos graxos, poedeiras comerciais.

\section{Yolk fatty acids and egg components from layers fed diets with coconut meal}

\begin{abstract}
The objective of this work was to evaluate the effects of coconut meal (CM) inclusion in commercial layer diets and feeding time, on egg components and yolk fatty acid composition. The experiment followed a factorial design 5x2, with five levels of CM inclusion (0, 5, 10, 15 and 20\%) and two feeding time (14 and 28 days). Parameters evaluated included: egg weight, and albumen, yolk and shell percentages, as well as solids, lipids and fatty acid profile of the yolk. The inclusion of CM and feeding time affected the yolk content of myristic acid which increased with CM level and with feeding time. The levels of stearic and oleic acids in the yolk varied with feeding time and were higher in the eggs after 28 days. Polyunsaturated to saturated fatty acid ratio in yolk decreased, when dietary CM levels were higher than $10 \%$, and increased with longer feeding time. The use of CM in laying hen diets does not influence egg composition but increases myristic acid content of the yolk.
\end{abstract}

Index terms: egg yolk, total solids, fatty acid profile, laying hens.

\section{Introdução}

Os dados apresentados pela USDA (2000) indicam que os países desenvolvidos têm apresentado um decréscimo no consumo per capita anual de ovo, que passou de 303 para 256 unidades, durante os últimos 35 anos. De acordo com o Anuário (2003), o Brasil registrou consumo per capita de aproximadamente 81,7 ovos em 2002 e 87,5 em 2003, crescimento de 8\%, sendo a Região Sudeste a que mais consome (176 ovos por habitante por ano).
A alimentação das poedeiras representa a maior parcela do custo de produção e pequenas melhorias, na eficiência de utilização dos nutrientes das rações, que podem resultar em grandes economias. Experimento realizado por Braga (2003), que utilizou o farelo de coco (FC) na alimentação de poedeiras comerciais, demonstrou vantagens relacionadas ao consumo de ração, à conversão alimentar e, ainda, ao custo de produção do ovo.

A quantidade e a natureza dos lipídios dos alimentos de origem animal têm preocupado os consumidores. 
Em relação aos ovos, a atenção se volta para a composição em colesterol e ácidos graxos da fração lipídica da gema, que apresenta: 8,7 g de ácidos graxos saturados; 13,2 g de ácidos graxos monoinsaturados; 3,4 g de ácidos graxos poliinsaturados; e $1.120 \mathrm{mg}$ de colesterol, por $100 \mathrm{~g}$ de gema fresca (Holland et al., 1997).

Segundo Grobas \& Mateos (1996), dos componentes do ovo, os lipídios são os mais fáceis de serem alterados mediante a manipulação da dieta das aves. A composição dos ácidos graxos do ovo, particularmente o seu conteúdo em poliinsaturados, pode variar conforme o tipo de dieta da galinha. Para Simopoulos (2000), os ácidos graxos da gema, especialmente o palmítico e o esteárico, são pouco alterados em conseqüência de modificações dietéticas. Para Fennema (1993), a quantidade de ácidos graxos saturados não varia com as modificações da dieta animal, porém, ocorre aumento do ácido linoléico e decréscimo do ácido oléico, ao se elevar a taxa de ácidos graxos poliinsaturados da dieta.

O farelo de coco (FC), um subproduto da extração do óleo de coco, vem sendo incorporado à alimentação animal, sobretudo por sua disponibilidade na Região Nordeste. Andriguetto (1988) reportou que a utilização do FC, por seu conteúdo em proteína bruta (22 a 26\%), poderá representar importante fonte alternativa de proteínas, especialmente para as áreas tropicais com limitações para a produção de ração animal.

Vasconcelos \& Brandão (1995) concluíram que a adição de até $20 \%$ de farelo de coco, em dietas iniciais de frango de corte, não afetou o ganho de peso, o consumo de ração e a conversão alimentar das aves. Segundo Braga et al. (2005), a inclusão de FC, em níveis de até $15 \%$ na ração de poedeiras comerciais, pode ser realizada sem prejudicar o desempenho das aves.

Embora seja de grande interesse o uso de fontes alternativas para a alimentação animal, é limitada a utilização de ingredientes alternativos na formulação das rações de poedeiras, uma vez que sua inclusão pode implicar em alterações indesejáveis quanto ao valor nutricional do ovo. $\mathrm{O}$ uso de estratégias nutricionais para melhorar a qualidade e a composição dos produtos de origem animal, utilizados na alimentação humana, tem se constituído no elo entre a produção animal, a tecnologia de alimentos e a nutrição humana.

Este trabalho teve como objetivo avaliar o efeito da inclusão do farelo de coco na ração e do tempo de alimentação de poedeiras comerciais, sobre os ácidos graxos da gema e os componentes do ovo.

\section{Material e Métodos}

Foram avaliados os ovos de poedeiras comerciais da linhagem Hy-Line, com 76 semanas de idade, alimentadas com rações com diferentes níveis de inclusão de farelo de coco. A avaliação dos ovos foi realizada aos 14 e 28 dias, depois de iniciada a alimentação das aves com as rações experimentais.

O delineamento experimental utilizado foi o inteiramente casualizado, em esquema fatorial $5 \mathrm{x} 2$, tendo sido cinco níveis de inclusão do FC e dois tempos de alimentação com as rações experimentais. Cada ração experimental foi oferecida a um grupo de 18 aves, divididas em três repetições de seis aves, num total de 90 aves.

As rações experimentais consistiram de uma ração testemunha sem farelo de coco ( $0 \%$ FC) e quatro rações com a inclusão desse ingrediente nos níveis de 5, 10, 15 e $20 \%$. As rações foram formuladas para conter níveis iguais de energia metabolizável, proteína bruta, cálcio, fósforo disponível, sódio, metionina e metionina + cistina (Tabela 1), tendo-se considerado as exigências nutricionais propostas no manual da linhagem e a composição dos alimentos constante na tabela da Embrapa (1991).

Aos 14 e 28 dias de alimentação com as rações experimentais, os ovos de cada repetição foram coletados e, em seguida, pesados individualmente para a determinação do peso médio. Do total de ovos coletados de cada repetição, foram selecionados três para a determinação dos porcentuais de casca, gema e albúmen.

As gemas foram separadas, pesadas e colocadas em um recipiente, homogeneizadas e congeladas em freezer a $-20^{\circ} \mathrm{C}$, para determinação posterior dos porcentuais de sólidos totais, lipídios totais e perfil de ácidos graxos. As cascas foram lavadas, secadas à temperatura ambiente por 48 horas e, logo depois, pesadas. O peso do albúmen foi obtido por diferença entre o peso do ovo e o peso do conjunto (gema e casca). A porcentagem de cada um dos constituintes do ovo foi determinada em relação ao peso do ovo.

Os sólidos totais das gemas foram determinados mediante o cálculo da diferença entre 100 e o porcentual de umidade, o qual foi obtido por meio de secagem, de aproximadamente $5 \mathrm{~g}$ de gema, em estufa a $104^{\circ} \mathrm{C}$, durante 16 horas. Os lipídios totais da gema foram extraídos mediante hidrólise ácida, conforme técnica descrita pela Association of Official Analytical Chemists (1990). 
O preparo das amostras, para a determinação do perfil de ácidos graxos nas gemas dos ovos, foi realizado pelo método da metilação direta (Wang et al., 2000). Aproximadamente $50 \mathrm{mg}$ de gema, previamente descongelada e homogeneizada, foram utilizados diretamente em tubos de ensaio, aos quais foram adicionados $1 \mathrm{~mL}$ de hexano e $3 \mathrm{~mL}$ de HCL $3 \mathrm{~N}$ em metanol. As amostras permaneceram em banho-maria, a $95^{\circ} \mathrm{C}$ durante 1 hora e, logo após, foram resfriadas à temperatura ambiente. Foram acrescentados $8 \mathrm{~mL}$ de solução salina $(\mathrm{NaCl} 0,88 \%)$ e $3 \mathrm{~mL}$ de hexano às amostras, que foram agitadas por 40 seg e, logo após, deixadas em repouso durante 4 horas. A camada formada na superfície dos tubos foi recolhida e armazenada em vidros sob refrigeração, com proteção de papel alumínio, para posterior análise cromatográfica.

Para a identificação dos ácidos graxos, pelo tempo de retenção cromatográfica, foram utilizados 100 mg da mistura de padrões com 19 ésteres metílicos de ácidos graxos C-8 a C-22 (Supelco 189-20), dissolvidos em $10 \mathrm{~mL}$ de hexano. A quantificação dos ácidos graxos utilizou como padrão interno o éster metílico do ácido nonadecanóico (C 19:0) (Sigma-Aldrich № 5377), em solução de concentração $5.000 \mathrm{mg} \mathrm{L}^{-1}$ de hexano.
As curvas de calibração para os ácidos graxos padrão foram obtidas com alíquotas de 5, 10, 15, 20, 25 e $50 \mu \mathrm{L}$ da solução-padrão, as quais foram transferidas para frascos de cromatografia gasosa com $1 \mu \mathrm{L}$ da solução do padrão interno. $\mathrm{O}$ volume dos frascos foi completado com hexano até $100 \mu \mathrm{L}$. As injeções de padrões e amostras no cromatógrafo foram de $1 \mu \mathrm{L}$. A partir dos cromatogramas, foram obtidos os valores das áreas dos picos de cada ácido graxo padrão e padrão interno. A razão entre estas áreas e a concentração dos padrões foi utilizada para construir as curvas de calibração.

Foram transferidos $99 \mu \mathrm{L}$ do extrato hexânico das amostras para frascos cromatográficos, com $1 \mu \mathrm{L}$ de solução do padrão interno, para as análises cromatográficas. Foi injetado $1 \mu \mathrm{L}$ desta solução em cromatógrafo de gás, equipado com detector de ionização de chama e coluna capilar SP 2560 Supelco (100 m x 0,25 mm D.I. x 0,2 $\mu \mathrm{m}$ ). As condições operacionais do cromatógrafo foram: temperatura de $250^{\circ} \mathrm{C}$ para injetor e detector; temperatura inicial de $160^{\circ} \mathrm{C}$ para a coluna, com aumento de $3,5^{\circ} \mathrm{C} \mathrm{min}{ }^{-1}$, e temperatura final de $240^{\circ} \mathrm{C}$; "split ratio" de $100: 1$ e hidrogênio como gás de arraste, em fluxo de 0,1 mL min-1.

Tabela 1. Composição porcentual e calculada de rações com farelo de coco fornecidas a poedeiras comerciais.

\begin{tabular}{|c|c|c|c|c|c|}
\hline \multirow[t]{2}{*}{ Ingredientes $(\%)$} & \multicolumn{5}{|c|}{ Níveis de farelo de coco $(\%)$} \\
\hline & 0 & 5 & 10 & 15 & 20 \\
\hline Milho & 57,53 & 57,19 & 55,10 & 53,07 & 50,61 \\
\hline Farelo de soja & 25,30 & 22,57 & 20,09 & 17,56 & 15,64 \\
\hline Óleo de soja & 2,67 & 2,67 & 2,67 & 2,67 & 2,67 \\
\hline Calcário & 8,64 & 8,66 & 8,67 & 8,68 & 8,69 \\
\hline Fosfato bicálcico & 1,54 & 1,52 & 1,50 & 1,48 & 1,46 \\
\hline Suplemento vitamínico ${ }^{(1)}$ & 0,20 & 0,20 & 0,20 & 0,20 & 0,20 \\
\hline Suplemento mineral ${ }^{(2)}$ & 0,10 & 0,10 & 0,10 & 0,10 & 0,10 \\
\hline DL-Metionina 99\% & 0,08 & 0,08 & 0,09 & 0,09 & 0,10 \\
\hline L-Lisina $\mathrm{HCl}$ & 0,00 & 0,00 & 0,03 & 0,09 & 0,12 \\
\hline Antioxidante $^{(3)}$ & 0,02 & 0,02 & 0,02 & 0,02 & 0,02 \\
\hline Sal comum & 0,37 & 0,37 & 0,37 & 0,37 & 0,37 \\
\hline Inerte $^{(4)}$ & 3,55 & 1,60 & 1,13 & 0,65 & 0,00 \\
\hline Pigmento $^{(5)}$ & 0,00 & 0,02 & 0,03 & 0,02 & 0.02 \\
\hline Total & 100,00 & 100,00 & 100,00 & 100,00 & 100,00 \\
\hline \multicolumn{6}{|l|}{ Composição calculada } \\
\hline Proteína bruta (\%) & 16,50 & 16,50 & 16,50 & 16,50 & 16,72 \\
\hline Extrato etéreo (\%) & 7,86 & 9,89 & 13,33 & 14,26 & 15,82 \\
\hline Fibra bruta (\%) & 2,62 & 3,08 & 3,52 & 3,96 & 4,43 \\
\hline Cálcio (\%) & 3,80 & 3,80 & 3,80 & 3,80 & 3,80 \\
\hline Fósforo disponível (\%) & 0,38 & 0,38 & 0,38 & 0,38 & 0,38 \\
\hline Sódio (\%) & 0,18 & 0,18 & 0,18 & 0,18 & 0,18 \\
\hline Lisina (\%) & 0,85 & 0,80 & 0,79 & 0,79 & 0,79 \\
\hline Metionina (\%) & 0,34 & 0,34 & 0,34 & 0,34 & 0,34 \\
\hline Metionina + cistina $(\%)$ & 0,61 & 0,61 & 0,61 & 0,60 & 0,60 \\
\hline
\end{tabular}


Com base nos valores de concentração obtidos, foi calculada a relação de ácidos graxos poliinsaturados (C18:3)/ ácidos graxos saturados (C14:0 + C16:0 + C18:0).

A análise estatística dos dados foi realizada pelo procedimento GLM (SAS Institute, 2000) para um modelo fatorial. Procedeu-se às análises de variância e de regressão, em que os graus de liberdade referentes aos níveis de inclusão do FC na ração, excluindo-se o nível zero de inclusão, foram desdobrados em polinômios, para se estabelecer a curva que melhor descrevesse o comportamento dos dados. Também, foi realizada a comparação da média dos demais níveis de inclusão do FC, em relação ao nível zero, pelo teste de Dunnett (5\% de probabilidade). Em relação ao tempo de alimentação (14 e 28 dias), as médias foram comparadas pelo teste t (5\% de probabilidade).

\section{Resultados e Discussão}

Para todas as variáveis avaliadas, na presente pesquisa, não houve interação significativa entre o nível de inclusão de FC e o tempo de alimentação das aves, com as rações experimentais.

A inclusão do FC, em níveis de até $20 \%$, e o tempo de alimentação não tiveram efeito significativo sobre o peso dos ovos, porcentuais de casca, gema e albúmen, umidade, sólidos totais e lipídios totais (Tabelas 2 e 3). Entretanto a proporção de ácidos graxos foi influenciada, significativamente, pelos tratamentos (Tabela 4).

O efeito da inclusão do FC nas rações de poedeiras sobre o peso dos ovos, reportado na literatura, tem sido controverso. Wignjosoesastro et al. (1972) utilizaram o FC em níveis de 0, 10, 20, 30 e 40\%, com e sem adição de óleo de coco, e verificaram redução significativa sobre o peso dos ovos, com o aumento dos níveis de inclusão do FC nas rações sem adição de óleo. Resultado

Tabela 2. Peso médio e porcentuais de casca, gema e albúmen do ovo de poedeiras comerciais, alimentadas com rações com diferentes níveis de farelo de coco (FC).

\begin{tabular}{ccccc}
\hline $\begin{array}{c}\text { Nível de inclusão } \\
\text { de FC }(\%)\end{array}$ & $\begin{array}{c}\text { Peso médio } \\
(\mathrm{g})\end{array}$ & $\begin{array}{c}\text { Casca } \\
(\%)\end{array}$ & $\begin{array}{c}\text { Gema } \\
(\%)\end{array}$ & $\begin{array}{c}\text { Albúmen } \\
(\%)\end{array}$ \\
\hline 0 & 62,77 & 8,18 & 28,44 & 63,38 \\
5 & 61,61 & 8,48 & 27,48 & 63,97 \\
10 & 63,98 & 8,26 & 27,52 & 63,93 \\
15 & 64,21 & 8,14 & 27,53 & 64,36 \\
20 & 61,53 & 7,97 & 27,30 & 64,77 \\
\hline Tempo de alimentação (dias) & & & \\
14 & 63,24 & 8,15 & 27,45 & 64,39 \\
28 & 62,40 & 8,26 & 27,86 & 63,77 \\
\hline CV $(\%)$ & 3,68 & 3,63 & 3,17 & 1,48 \\
\hline
\end{tabular}

semelhante foi observado por Panigrahi (1989). Entretanto, Braga et al. (2005) não observaram diferença significativa entre o peso médio dos ovos, de aves alimentadas com rações com até $20 \%$ de FC, o que está em concordância com os resultados obtidos no presente experimento (Tabela 2).

Leeson \& Summers (1997) reportaram que a proteína, os aminoácidos e o ácido linoléico são os fatores nutricionais mais importantes que afetam o peso do ovo. No presente experimento, as poedeiras receberam rações formuladas para conter níveis iguais de energia metabolizável, proteína bruta, cálcio, fósforo disponível, sódio, metionina e metionina + cistina. Provavelmente, os nutrientes ingeridos pelas aves foram suficientes, para que o peso médio dos ovos tenha se mantido estável.

O comprometimento da digestibilidade dos nutrientes das rações, em razão do aumento da fibra bruta, tem sido associado à baixa no desempenho e à queda no peso dos ovos das poedeiras alimentadas com altos níveis de FC (Wignjosoesastro et al., 1972; Panigrahi, 1989; Rodríguez-Palenzuela et al., 1998). Com a inclusão do farelo de coco (Tabela 1), houve aumento da fibra bruta da ração, que passou de $2,62 \%$ na ração com $0 \%$ de FC, para 4,43\% na ração com $20 \%$ de FC; entretanto, esse aumento não afetou o peso médio dos ovos (Tabela 2).

Os valores médios para porcentagens de albúmen, gema e casca, e para conteúdo de sólidos totais na gema e albúmen dos ovos, dos diferentes tratamentos, estão de acordo com os relatados na literatura. Os ovos de poedeiras comerciais apresentam, em média, 58\% de albúmen, $31 \%$ de gema e $11 \%$ de casca, e o conteúdo de sólidos totais, para o albúmen e gema, é em torno de 12 e 50\%, respectivamente (Stadelman \& Cotterill, 1986).

Quanto ao conteúdo de lipídios totais da gema do ovo, Fennema (1993) afirmou que varia entre 32 e 35\% e

Tabela 3. Umidade, sólidos totais e lipídios totais da gema do ovo de poedeiras comerciais, alimentadas com rações com diferentes níveis de farelo de coco (FC).

\begin{tabular}{cccc}
\hline $\begin{array}{c}\text { Nível de inclusão } \\
\text { de FC }(\%)\end{array}$ & $\begin{array}{c}\text { Umidade } \\
(\%)\end{array}$ & $\begin{array}{c}\text { Sólidos totais } \\
(\%)\end{array}$ & $\begin{array}{c}\text { Lipídios totais } \\
(\%)\end{array}$ \\
\hline 0 & 48,62 & 51,38 & 31,07 \\
5 & 49,32 & 50,67 & 30,93 \\
10 & 49,65 & 50,35 & 30,87 \\
15 & 49,16 & 50,84 & 30,73 \\
20 & 48,84 & 51,16 & 31,26 \\
\hline Tempo de alimentação (dias) & & \\
14 & 48,88 & 51,12 & 30,99 \\
28 & 49,35 & 50,65 & 30,96 \\
\hline CV $(\%)$ & 1,43 & 1,38 & 2,04 \\
\hline
\end{tabular}


atribuiu esta variação mais à linhagem da ave do que à dieta oferecida. Neste experimento, a linhagem não constituiu variável de estudo, no entanto, com o aumento dos níveis de FC na ração, houve uma crescente oferta de fibras e gordura saturada às poedeiras. Contudo, não foi observada diferença significativa do conteúdo de lipídios totais da gema, dos ovos de aves que receberam rações com FC, quando comparados aos de aves que receberam a ração testemunha (Tabela 3). Os lipídios totais da gema variaram de 30,73 a $31,26 \%$, valores abaixo daqueles reportados por Fennema (1993).

Rodríguez-Palenzuela et al. (1998) relataram que o alto teor de fibra do FC e sua elevada absorção de água podem levar a um consumo menor de ração e afetar a produção e o peso do ovo. Apesar do aumento do teor de fibra, com o aumento da inclusão de FC, neste experimento, não foram observadas alterações no peso ou na composição do ovo. É válido ressaltar que a fibra é necessária ao crescimento microbiano normal e à síntese de ácidos orgânicos, indispensáveis à saúde do ecossistema intestinal das aves (Silva et al., 2002).

A inclusão do FC alterou, significativamente, apenas a concentração do ácido mirístico na gema (Tabela 4). $\mathrm{Na}$ análise de regressão, foi observado efeito linear crescente, de acordo com a equação $y=-0,30+0,22 x$; $\mathrm{R}^{2}=0,68$, tendo havido, portanto, aumento de $0,22 \mathrm{mg}$ de ácido mirístico por $100 \mathrm{~g}$ de gema, para cada $1 \%$ de inclusão do FC na ração. Comparando-se com a ração testemunha ( $0 \%$ FC), a inclusão de FC, em todos os níveis, promoveu um aumento significativo na concentração de ácido mirístico na gema, de acordo com o teste de Dunnett.

Quanto ao tempo de alimentação, foi observado aumento significativo na concentração do ácido mirístico, na gema dos ovos de aves alimentadas com as rações com FC, durante 28 dias, em relação àqueles das aves alimentadas durante 14 dias. O oposto ocorreu com as concentrações dos ácidos esteárico e oléico, que diminuíram significativamente, para o período de 28 dias. Esses resultados sugerem que a composição dos ácidos graxos poderá se tornar estável, provavelmente, em período superior aos 28 dias usados neste experimento.

Wignjosoesastro et al. (1972) ao avaliar os efeitos da inclusão do FC em níveis de 0, 10, 20, 30 e 40\%, com a adição de 0 e $10 \%$ de óleo de coco, demonstraram que o conteúdo de gordura dos ovos não foi significativamente alterado pelos tratamentos, mas a adição do óleo de coco aumentou os teores de ácido láurico e mirístico e reduziu os teores dos ácidos esteárico, oléico e linoléico.

Era esperado que a inclusão de FC na ração das poedeiras pudesse representar uma alternativa viável, do ponto de vista tecnológico e da nutrição humana, sem afetar a composição lipídica da gema do ovo, apesar do conteúdo de ácidos graxos saturados presentes naquele alimento. Conforme Grobas \& Mateos (1996), altas concentrações de ácidos graxos saturados, na dieta das galinhas, provocam poucas modificações no perfil de ácidos graxos do ovo.

Na nutrição humana, dietas com altas concentrações de ácidos graxos saturados de cadeia longa promovem aumento do colesterol plasmático, quando comparados com altas concentrações de monoinsaturados e poliinsaturados. Contudo, existem diferenças quanto aos efeitos hipercolesterolêmicos dos ácidos graxos saturados, pois o láurico (C12:0), o mirístico (C14:0) e o palmítico (C16:0) elevam os níveis de colesterol plasmático, enquanto o esteárico (C18:0) não apresenta

Tabela 4. Principais ácidos graxos da gema do ovo (mg $100 \mathrm{mg}^{-1}$ ) de poedeiras comerciais, alimentadas com rações com diferentes níveis de farelo de coco (FC) ${ }^{(1)}$.

\begin{tabular}{|c|c|c|c|c|c|c|}
\hline \multirow[t]{2}{*}{ Nível de inclusão de FC (\%) } & \multicolumn{6}{|c|}{ Ácidos graxos } \\
\hline & $\begin{array}{c}\text { Mirístico } \\
\text { C14:0 }\end{array}$ & $\begin{array}{c}\text { Palmítico } \\
\text { C16:0 }\end{array}$ & $\begin{array}{c}\text { Palmitoléico } \\
\text { C16:1 }\end{array}$ & $\begin{array}{c}\text { Esteárico } \\
\text { C18:0 }\end{array}$ & $\begin{array}{l}\text { Oléico } \\
\text { C18:1 }\end{array}$ & $\begin{array}{c}\text { Linolênico } \\
\text { C18:3 }\end{array}$ \\
\hline 0 & 0,00 & 0,40 & 0,25 & 0,85 & 4,42 & 0,46 \\
\hline 5 & $0,16^{*}$ & 0,42 & 0,35 & 0,87 & 4,34 & 0,50 \\
\hline 10 & $0,12^{*}$ & 0,38 & 0,20 & 0,73 & 4,55 & 0,38 \\
\hline 15 & $0,24 *$ & 0,39 & 0,26 & 0,83 & 5,28 & 0,43 \\
\hline 20 & $0,48^{*}$ & 0,54 & 0,32 & 0,91 & 2,97 & 0,57 \\
\hline \multicolumn{7}{|l|}{ Tempo de alimentação (dias) } \\
\hline 14 & $0,15 \mathrm{a}$ & $0,47 \mathrm{a}$ & $0,29 a$ & $1,02 \mathrm{a}$ & $6,06 a$ & $0,51 \mathrm{a}$ \\
\hline 28 & $0,21 b$ & $0,39 \mathrm{a}$ & $0,26 a$ & $0,69 b$ & $2,53 b$ & $0,44 \mathrm{a}$ \\
\hline $\mathrm{CV}(\%)$ & 15,98 & 34,66 & 44,05 & 30,25 & 46,84 & 35,20 \\
\hline
\end{tabular}

(1)Médias com letras diferentes, nas colunas, diferem entre si pelo teste t, a 5\% de probabilidade. *Significativo em relação ao nível zero de inclusão, pelo teste de Dunnett, a $5 \%$ de probabilidade; efeito linear $\left(\mathrm{y}=-0,30+0,022 \mathrm{x} ; \mathrm{R}^{2}=0,68\right)$. 
o mesmo efeito e é, portanto, considerado neutro (Banskalieva et al., 2000).

Os estudos de população têm revelado associação negativa entre ingestão de ácidos graxos monoinsaturados e poliinsaturados e incidência de doenças cardiovasculares (Jonnalagadda et al., 1996), assim como uma associação com efeitos positivos sobre as concentrações das lipoproteínas LDL e HDL (Sirtori et al., 1986; Mensink \& Katan, 1989; Lima et al., 2000). Segundo esses autores, não é possível afirmar que tipo de ácido graxo insaturado possui maior potencial benéfico para a saúde humana; é portanto, necessária a realização de mais pesquisas nesse âmbito.

De acordo com a análise de regressão, a inclusão de FC em níveis de 5 até $20 \%$ da ração não influenciaram, significativamente, a relação de ácidos graxos poliinsaturados para ácidos graxos saturados (P/S), dos lipídios da gema do ovo (Tabela 5). Entretanto, de acordo com o teste de Dunnett, os níveis de 10, 15 e 20\% de inclusão de FC produziram redução da relação $\mathrm{P} / \mathrm{S}$, quando comparada à da ração testemunha $(0 \%$ FC). Em relação ao tempo de alimentação, observou-se que a relação P/S na gema do ovo foi maior, decorridos 28 dias de alimentação.

De acordo com Hargis \& Van Elswyk (1993), aumentar os níveis de gordura saturada na dieta tem pouca influência sobre a composição da gordura da gema. Por sua vez, quando se adicionam às dietas gorduras ricas em ácidos graxos saturados de cadeia curta, apenas os ácidos de cadeia curta mais abundantes são depositados na gema e em porcentuais sempre muito baixos, como ocorre, por exemplo, com a adição do óleo de coco, em que somente o láurico (C12:0) se deposita no ovo e em porcentuais menores que $2 \%$ do total dos

Tabela 5. Relação P/S (ácidos graxos poliinsaturados/saturados) da gema do ovo de poedeiras comerciais, alimentadas com rações com diferentes níveis de farelo de coco (FC) ${ }^{(1)}$.

\begin{tabular}{cccc}
\hline $\begin{array}{c}\text { Nível de inclusão } \\
\text { de FC (\%) }\end{array}$ & $\begin{array}{c}\text { Ácidos graxos } \\
\text { poliinsaturados }\end{array}$ & $\begin{array}{c}\text { Ácidos graxos } \\
\text { saturados }\end{array}$ & $\mathrm{P} / \mathrm{S}$ \\
\hline 0 & 0,46 & 1,26 & 0,36 \\
5 & 0,50 & 1,42 & 0,35 \\
10 & 0,27 & 1,23 & $0,31^{*}$ \\
15 & 0,43 & 1,40 & $0,31^{*}$ \\
20 & 0,57 & 1,90 & $0,30^{*}$ \\
\hline Tempo de alimentação (dias) & & \\
14 & 0,51 & 1,70 & $0,30 \mathrm{a}$ \\
28 & 0,44 & 1,29 & $0,34 \mathrm{~b}$ \\
\hline
\end{tabular}

${ }^{(1)}$ Médias com letras diferentes, nas colunas, diferem entre si pelo teste t, a 5\% de probabilidade. *Significativo em relação ao nível zero de inclusão, pelo teste de Dunnett, a 5\% de probabilidade. ácidos graxos. Segundo estes pesquisadores, a rápida degradação dos ácidos graxos de cadeia curta e a sua conversão em ácidos graxos de cadeia mais longa, no fígado das poedeiras, são responsáveis pela baixa deposição de ácidos graxos de cadeia curta na gema dos ovos.

A Associação Americana do Coração (AHA) tem recomendado relação P/S de 1/1, em razão dos vários estudos nutricionais que reportam a relação entre ácidos graxos saturados e o risco de doenças cardiovasculares (Pardío et al., 2000), enquanto se preconiza a proporção 1:2:1,5 para os ácidos graxos saturados, monoinsaturados e poliinsaturados (Lima et al., 2000).

O uso de rações de postura, com FC, durante 28 dias, deve ser analisado criteriosamente, em razão do incremento de ácido mirístico e redução de ácido cis-9-oléico na gema. Considerando-se a importância da relação P/S nos alimentos consumidos pela população, é recomendável que a inclusão do FC, nas rações de poedeiras comerciais, não ultrapasse o nível de 5\%, pois inclusão acima desse nível diminui a relação P/S da gema do ovo.

\section{Conclusões}

1. O peso médio do ovo e os porcentuais de casca, gema e albúmen, bem como a umidade, os sólidos totais e os lipídios totais da gema não são alterados com a inclusão de até $20 \%$ de farelo de coco na ração das poedeiras.

2. O aumento da inclusão de farelo de coco, na ração das poedeiras comerciais, resulta em aumento proporcional da concentração do ácido mirístico (C14:0) na gema do ovo, e é maior aos 28 dias depois de iniciada a alimentação.

3. As concentrações de ácido esteárico (C18:0) e cis9-oléico (C18:1) da gema do ovo diminuem com o tempo de alimentação das poedeiras; as proporções destes ácidos não são influenciadas pela inclusão do farelo de coco.

\section{Agradecimentos}

À Fundação Cearense de Apoio ao Desenvolvimento Científico-Tecnológico (Funcap), por bolsa concedida; ao Sr. Rivelino Cavalcante, do Dep. de Química Analítica e Físico-Química, da Universidade Federal do Ceará (UFC), pelo auxílio nas análises por cromatografia de gás; aos Srs. Luis Alves Bitu e Rozelúcia Barrozo, do DTA/UFC, pela auxílio nas determinações de lipídios totais, umidade e sólidos totais. 


\section{Referências}

ANDRIGUETTO, J.M. Nutrição animal. 4.ed. São Paulo: Nobel, 1988. v.1, 395p.

ANUÁRIO 2004 da Avicultura Industrial. São Paulo: Ediagro, v.95, 2003.

ASSOCIATION OF OFFICIAL ANALYTICAL CHEMISTS (Arlington, Estados Unidos). Official methods of analysis of the AOAC. $15^{\text {th }}$ ed. Arlington, 1990. 1250p.

BANSKALIEVA, V.; SAHLU, T.; GOETSCH, A.L. Fatty acid composition of goat muscles and fat depots: a review. Small Ruminant Research, v.37, p.255-268, 2000.

BRAGA, C.V.P. Efeito da inclusão do farelo de coco em rações de poedeiras. 2003. 45p. Dissertação (Mestrado) - Universidade Federal do Ceará, Fortaleza.

BRAGA, C.V.; FUENTES, M.F.F.; FREITAS, E.R.; CARVALHO, L.E.; SOUSA, F.M.; BASTOS, S.C. Efeito da inclusão do farelo de coco em ração para poedeiras comerciais. Revista Brasileira de Zootecnia, v.34, p.76-80, 2005.

EMBRAPA. Centro Nacional de Pesquisa de Suínos e Aves (Concórdia, SC). Tabela de composição química e valores energéticos de alimentos para aves e suínos. 3.ed. Concórdia, 1991. 97p. (Embrapa-CNPSA. Documentos, 19).

FENNEMA, O.R. Química de los alimentos. Zaragoza: Acribia, 1993. 1096p.

GROBAS, S.; MATEOS, G.G. Influencia de la nutrición sobre la composición nutricional del huevo. In: CURSO DE ESPECIALIZACIÓN FEDNA, 12., 1996, Madrid. Avances en nutrición y alimentación animal. Madrid: Fedna, 1996. p.219244.

HARGIS, P.S.; VAN ELSWYK, M.E. Manipulating the fatty acid composition of poultry meat and eggs for the health conscious consumer. World's Poultry Science Journal, v.49, p.251-264, 1993.

HOLLAND, B.; WELCH, A.A.; UNWIN, I.D.; BUSS, D.H.; PAUL, A.A.; SOUTHGATE, D.A.T. The composition of foods. $5^{\text {th }}$ ed. Cambridge: Redwood Books, 1997. 462p.

JONNALAGADDA, S.S.; MUSTAD, V.A.; YU, S.; ETHERTON, T.D.; KRIS-ETHERTON, P.M. Effects of individual fatty acids on chronic diseases. Nutrition Today, v.31, p.90-116, 1996.

LEESON, S.; SUMMERS, J.D. Commercial poultry nutrition. $2^{\text {nd }}$ ed. Guelph: University Books, 1997. 370p.

LIMA, F.E.L.; MENEZES, T.N.; TAVARES, M.P.; SZARFARC, S.C.; FISBERG, R.M. Ácidos graxos e doenças cardiovasculares: uma revisão. Revista de Nutrição, v.13, p.73-80, 2000.

MENSINK, R.P.; KATAN, M.B. Effects of a diet enriched with monounsaturated or polyunsaturated fatty acids on levels of low density and high density lipoproteins cholesterol in healthy women and men. New England Journal of Medicine, v.321, p.436-441, 1989.

PANIGRAHI, S. Effects on egg production of including high residual lipid copra meal in laying hen diets. British Poultry Science, v.30, p.305-312, 1989.

PARDÍO, V.T.; LANDÍN, L.A.; WALISZEWSKI, K.N.; PÉREZGIL, F.; DÍAZ, L.; HERNÁNDEZ, B. The effect of soybean soapstock on the quality parameters and fatty acid composition of the hen egg yolk. Poultry Science, v.84, p.148-157, 2000.

RODRÍGUEZ-PALENZUELA, P.; GARCÍA, J.; DE BLAS, C. Fibra soluble y su implicación en nutrición animal: enzimas y probióticos. In: CURSO DE ESPECIALIZACIÓN FEDNA, 14., 1998, Barcelona. Avances en nutrición y alimentación animal. Barcelona: FEDNA, 1998. p.227-240.

SAS INSTITUTE (Cary, Estados Unidos). SAS/STAT: user's guide. Version 6.12. Cary, 2000. 2v.

SILVA, J.H.V.; SILVA, E.L.; JORDÃO FILHO, J.; TOLEDO, R.S.; ALBINO, L.F.T.; RIBEIRO, M.L.G.; COUTO, H.P. Valores energéticos e efeitos da inclusão de farinha integral da vagem de algaroba (Prosopis juliflora (S.W.) D.C.) em rações de poedeiras comerciais. Revista Brasileira de Zootecnia, v.31, p.2235-2264, 2002.

SIMOPOULOS, A.P. Role of poultry products in enriching the human diet with n-3 PUFA. Human requirement for n-3 polyunsaturated fatty acids. Poultry Science, v.79, p.961-970, 2000.

SIRTORI, C.R.; TREMOLI, E.; GATTI, E.; MONTANARI, G.; SIRTORI, M.; COLLI, S.; GIANFRANCESCHI, G.; MADERNA, P.; DENTONE, C.Z.; TESTOLIN, G.; GALLI, C. Controlled evaluation of fat intake in the Mediterranean diet: comparative activities of olive oil and corn oil on plasma lipids and platelets in high risk patients. American Journal of Clinical Nutrition, v.44, p.635-642, 1986.

STADELMAN, W.J.; COTTERILL, O.J. Egg science and technology. $3^{\text {rd }}$ ed. Westport: Avi Pub. Co., 1986. 449p.

USDA. Agriculture statistics, 2000. Washington: Government Printing Office, 2000. 538p.

VASCONCELOS, R.Q.; BRANDÃO, J.S. Efeitos de níveis de farelo de coco na dieta inicial sobre o desempenho de frangos de corte. Revista Brasileira de Zootecnia, v.24, p.391-400, 1995.

WANG, Y.; SUNWOO, H.; CHERIAN, G.; SIM, J.S. Fatty acid determination in chicken egg yolk: a comparison of different methods. Poultry Science, v.79, p.1168-1171, 2000.

WIGNJOSOESASTRO, N.; BROOKS, C.C.; HERRICK, R.B. The effect of coconut meal and coconut oil in poultry rations on the performance of laying hens. Poultry Science, v.51, p.1126-1132, 1972.

Recebido em 7 de fevereiro de 2006 e aprovado em 31 de agosto de 2006 